\title{
ANALISIS KERENTANAN SOSIAL EKONOMI MASYARAKAT PETANI SAWIT DIKECAMATAN SUNGAI AUR KABUPATEN PASAMAN BARAT
}

\author{
Nurlatifah $^{1}$. Syafri Anwar ${ }^{2 \cdot}$ Yudi Antomi ${ }^{2 \cdot}$ \\ Program Studi Geografi (Nk) \\ Fakultas Ilmu Sosial, Universitas Negeri Padang \\ Email: nurlatifahlbs0704@gmail.com
}

\begin{abstract}
ABSTRAK
Penelitian ini bertujuan untuk membahas tentang analisis kerentanan sosial ekonomi masyarakat petani sawit di kecamatan sungai aur kabupaten Pasaman Barat.

Penelitian ini tergolong penelitian kuantitatif.Jumlah populasi adalah semua petani sawit yang ada di 22 jorong di kecamatan sungai aur. Dalam penelitian ini Pendekatan sampel menggunakan rumus Slovin (Bambang Prasetyo, 2006) dalam Yudi Antoni 2016 dengan perhitungan sampel berjumlah 99 orang. Teknik pengumpulan data yang digunakan adalah wawancara, observasi dan menggunakan data sekunder dari pemerintahan Nagari Batu Basa.Teknik analisis data yang digunakan dalam penelitian ini yaitu teknik scoring.

Hasil penelitian menemukan : (1) Tingkat kerentanan sosial petani sawit di kecamatan sungai aur dalam kategori sangat rentan (nilai >11) yaitu terdapat pada 8 jorong, kategori agak rentan (nilai 4-11) terdapat 7 jorong dan kategori tidak rentan (Nilai <4) terdapat 7 jorong (2) Tingkat kerentanan ekonomi petani sawit di kecamatan sungai aur kategori sangat rentan (nilai $>11$ ) yaitu terdapat pada 8 jorong, kategori agak rentan (nilai 4-11) terdapat 7 jorong dan kategori tidak rentan (Nilai <4) terdapat 7 jorong (3) Tingkat kerentanan perkebunan petani sawit di kecamatan sungai aur yang kategorikan sangat rentan (nilai $>6$ ) yaitu terdapat pada 9 jorong, kategori agak rentan (nilai 3-6) terdapat 5 jorong dan kategorikan tidak rentan (Nilai <3) terdapat 8 jorong.
\end{abstract}

Keyword: Kerentanan, Sosial, Ekonomi, perkebunan kelapa sawit.

ABSTRACT

This study aims to discuss about the analysis of socio-economic vulnerability of the community of oil palm farmers in the sub-district of the river district west pasaman.

This research is classified as quantitative research. The total population is all oil palm farmers in 22 jorong in the river aur district. In this research sample approach using Slovin formula (Bambang Prasetyo, 2006) in Yudi Antoni 2016 with the sample calculation amounted to 99 people. Data collection techniques used were interviews, observations and using secondary data from the Nagari Batu Basa government. Data analysis technique used in this research is scoring technique.

The results of the study found: (1) The level of social vulnerability of oil palm farmers in the sub-district of Sungai aur in the category of very vulnerable (value $>11$ ) is in 8 jorong, the category of vulnerable (4-11) there are 7 jorong, and the not vulnerable category <4) there are 7 jorong (2) The level of economic vulnerability of oil palm farmers in the river sub-district is very vulnerable category (value >11) which is in 8 jorong, the category of vulnerable (4-11) there are 7 jorong and the not vulnerable category <4) there are 7 jorong (3) The vulnerability level of oil palm plantation in Sungai Aur sub-district is categorized as very vulnerable (value $>$ 6) that is in 9 jorong, the category is vulnerable (3-6 value) there are 5 jorong and categorize not susceptible (Value <3) there are 8 jorong.

Keyword: Vulnerability, Social, Economic, oil palm plantation.

\footnotetext{
${ }^{1}$ Mahasiswa Program Studi Geografi untuk wisuda Maret 2018

${ }^{2}$ Dosen Jurusan Geografi Fakultas Ilmu Sosial Universitas Negeri Padang dan Pembimbing 1 Prof.Dr.Syafri Anwar, M.Pd dan Pembimbing 11 Dr. Yudi Antomi, M.Si
} 
Indonesia telah dikenal sebagai negara agraris.Hal ini disebabkan karena Indonesia memiliki luas lahan dan agroklimat yang sangat potensial untuk dikembangkan sebagai usaha pertanian.Indonesia juga sejak lama dikenal sebagai penghasil berbagai produk pertanian yang sangat dibutuhkan dan laku di pasar dunia. Di samping itu sumbangan sektor pertanian terhadap serapan tenaga kerja, pendapatan nasional dan devisa juga masih sangat tinggi (Mardikanto, 2007: 4).

Kelapa sawit adalah salah satu komoditi yang diharapkan mampu memberikan kontribusinya dalam perekonomian yang berasal dari sub-sektor perkebunan. Kelapa sawit sebagai tanaman penghasil minyak sawit dan inti sawit merupakan salah satu primadona tanaman perkebunan yang menjadi sumber penghasil devisa non migas bagi Indonesia. Cerahnya prospek komoditi minyak sawit dalam perdagangan minyak nabati dunia telah mendorong Pemerintah Indonesia untuk memacu pengembangan ekspor minyak kelapa sawit.

Menurut Lubis, A.U. (2008), minyak kelapa sawit mempunyai kemampuan daya saing yang cukup kompetitif dibanding minyak nabati lainnya, karena : a) produktivitas per-hektar cukup tinggi, b) ditinjau dari aspek gizi, minyak kelapa sawit tidak terbukti sebagai penyebab meningkatnya kadar kolesterol, bahkan mengandung beta karoten sebagai provitamin A. Tanaman kelapa sawit merupakan penghasil minyak nabati yang paling banyak yang mempunyai produktifitas yang lebih tinggi dibandingkan dengan tanaman penghasil minyak nabati lainnya.
Keberhasilan pengembangan kelapa sawit tidak terlepas dari ketersediaan bahan tanaman unggul dalam hal ini benih kelapa sawit. Pemilihan bahan tanaman yang tidak tepat akan menyebabkan kerugian, baik materi maupun waktu, karena benih kelapa sawit sulit dideteksi secara dini tetapi baru dapat diketahui setelah tanaman menghasilkan, yaitu \pm 30 bulan setelah tanam. Sejalan dengan itu agar diperoleh produksi yang tinggi dan keuntungan yang maksimal maka harus digunakan varietas kelapa sawit yang unggul. Ciri-ciri varietas kelapa sawit yang unggul yaitu sebagai berikut:

1. Berasal dari hasil pemuliaan serta telah diuji pada berbagai kondisi.

2. Tersedia sebagai bahan tanaman dalam jumlah yang dibutuhkan.

3. Berumur genjah.

4. Memiliki produksi dan kualitas minyak yang tinggi.

5. respon terhadap perlakuan yang diberikan.

6. Memiliki umur ekonomis cukup panjang.

7. Tahan terhadap penyakit dan toleran terhadap stress lingkungan.

8. Benih tersebut dihasilkan oleh pusat sumber benih kelapa sawit yang resmi ditunjuk pemerintah.

Pengembangan komoditi perkebunan melalui perluasan areal di Kabupaten Pasaman Barat kurang mendapat dukungan dari sub sistem pengadaan sarana produksi dan pengembangan industri hilirnya, akibatnya kebun yang berhasil dibangun produksinya relatif masih rendah dan produksinya dipasarkan dalam bentukproduk primer. Khususnya di 
Kecamatan Sungai Aur nilai ekspor produk perkebunan asal kecamatan ini cukup tinggi. Untuk itu peneliti tertarik untuk melakukan penelitian tentang "Analisis Kerentanan Sosial Ekonomi Masyarakat Petani Sawit DiKecamatan Sungai Aur Kabupaten Pasaman Barat" sehingga penelitian lebih mudah untuk di pahami.

\section{Tujuan Penelitian}

Adapun tujuan penelitian ini untuk mengetahui dan mendapatkan informasi, menganalisa dan membahas tentang Analisis Kerentanan Sosial Ekonomi Masyarakat Petani Sawit di Kecamatan Sungai Aur Kabupaten Pasaman Barat

\section{Metode Penelitian}

Metode yang digunakan dalam penelitian ini adalah mixed methods. Penelitian ini merupakan suatu langkah penelitian dengan menggabungkan dua bentuk penelitian yang telah ada sebelumnya yaitu penelitian kualitatif dan penelitian kuantitatif. Pendekatan yang dilakukan dalam penelitian ini adalah pendekatan spasial/keruangan yang menggambarkan kondisi nyata di lapangan.

\section{Tempat dan Lokasi Penelitian}

Penelitian ini akan dilaksanakan di Kecamatan Sungai Aur, Kabupaten Pasaman Barat, Sumatera Barat, Penetapan lokasi didasarkan atas pertimbangan bahwa Kecamatan Sungai Aur, Kabupaten Pasaman Barat merupakan salah satu daerah sentra pengembangan usaha tani Kelapa Sawit di Kabupaten Pasaman Barat. Penelitian ini dilakukan sekitar pada bulan desember 2017.Peta lokasi penelitian dapat dilihat pada gambar 1 .

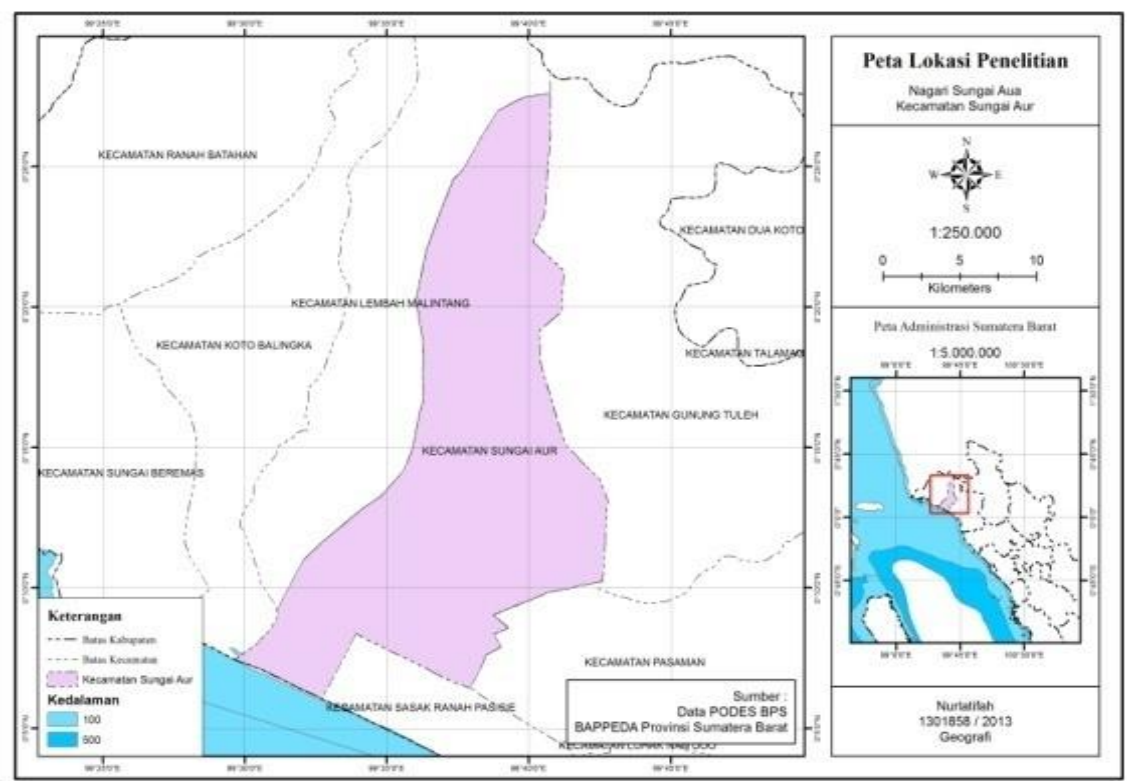

Gambar 1: Peta Lokasi Penelitian

\section{Populasi dan Sampel Penelitian}

Menurut Panbudu (2005 : 24) dikatakan bahwa : "Populasi adalah himpunan individu atau objek yang banyaknya terbatas atau tidak terbatas".

\section{Populasi Penelitian}

a. Populasi wilayah, yaitu seluruh daerah yang memiliki perkebunan kelapa sawit yang berada di 
Kecamatan Sungai Aur yang terdiri dari 22 Jorong.

b. Populasi penduduk, yaitu seluruh penduduk yang mempunyai mata pencaharian sebagai petani sawit.

\section{Sampel Penelitian}

Sampel adalah sebagian dari jumlah dan karakteristik yang dimiliki oleh populasi tersebut, ataupun bagian kecil dari anggota populasi yang di ambilmenurut prosedur tertentu sehingga dapat mewakili populasinya. Sampel yang akan diambil dari populasi tersebut harus betul-betul representatif atau dapat mewakili.Sampel penelitian merupakan sebagian petani sawit yang dianggap dapat mewakili populasi. Pendekatan sampel menggunakan rumus Slovin (Bambang Prasetyo, 2006) dalam Yudi Antoni 2016 sebagai berikut:

$$
\mathrm{n}=\frac{\mathrm{N}}{1+\mathrm{N} e^{2}}
$$

Keterangan :

$$
\begin{aligned}
& \mathrm{n}=\text { ukuran / besarnya sampel } \\
& \mathrm{N}=\text { ukuran / populasi } \\
& \mathrm{e}=\text { Toleransi kesalahan(error } \\
& \text { tolerance) } 10 \% \\
& \qquad n_{\text {petani }} \\
& =\frac{8.551}{1+8.551 * 0,1^{2}} \\
& =\frac{8551}{86,57} \\
& =98,77 \text { (99 orang) }
\end{aligned}
$$

\section{Teknik Pengumpulan Data}

Daerah analisis dari penelitian ini adalah Kecamatan Sungai Aur yang terdiri dari 22 jorong dengan studi khasusnya yaiturumah tangga petani sawit di kecamatan sungai aur.Data yang digunakan dalam penelitian ini adalah berupa data primer dan data sekunder.

\section{Teknik Analisis Data}

Analisis kerentanan ini dilakukan dengan metode skoring untuk masingmasing indikator/parameternya, setelah itu baru dilakukan pengkategorian/kelas kerentanannya, dalam penentuan kelas ini terlebih dulu ditentukan nilai interval kelasnya dengan tujuan untuk membedakan kelas kerentanan antara yang satu dengan yang lain. Rumus yang digunakan untuk membuat kelas interval adalah digunakan formula yang dikemukaan oleh Dibiyosaputro (1999) dalam hermon (2015), yaitu:

$$
\operatorname{Kerentanan}(I)=\frac{c-b}{k}
$$

dimana :

$$
\text { I : besar jarak interval kelas }
$$

$\mathrm{c}$ : jumlah skor tertinggi

b : jumlah skor terendah

$\mathrm{k}$ : Kelas interval kerentanan

\begin{tabular}{|c|c|c|}
\hline Katergori & Nilai & $\begin{array}{l}\text { Tingkat } \\
\text { Kerentanan }\end{array}$ \\
\hline Tinggi & $>29,34$ & $\begin{array}{l}\text { Sangat } \\
\text { Rentan }\end{array}$ \\
\hline Sedang & $\begin{array}{l}18,67- \\
29,34\end{array}$ & $\begin{array}{l}\text { Agak } \\
\text { Rendah }\end{array}$ \\
\hline Rendah & $<18,67$ & Tidak \\
\hline
\end{tabular}

Pada kerentanan sosial ekonomi dapat dijelaskan tentang kalsifikasi kerentanan sosial ekonomi, dimana semakin tinggi nilai suatu skor maka menunjukkah bahawa tingkat kerentanannya lebih tinggipula, untuk lebih jelasnya dapat dilihat pada tabel 1 dibawah yaitu:

Tabel 1

Klasifikasi Tingkat Kerentanan Sosial Ekonomi 


\begin{tabular}{|l|l|l|}
\hline & & Rentan \\
\hline
\end{tabular}

Sumber: Pengolahan Data 2018

Dari tabel 1 di atas menunjukkan bahwa semakin tinggi nilai suatu kategori memberikan gambaran sebuah kondisi yang semakin buruk terkait parameter bersangkutan, dan sebaliknya.Untuk memperoleh sumber penyebab kerentanan dilakukan dengan menelusuri parameter yang memiliki nilai tinggi sehingga rekomendasi penanganannya disesuaikan dengan tingkat masalah yang dihadapi.

Pada dasarnya yang dimaksud untuk kategori tinggi/ rentan disini yaitu daerah yang memiliki tingkat kerentanannya tinggi baik dari segi sosial, ekonomi ataupun perkebunan dan untuk kategori sedang/agak rentan yaitu daerah yang memiliki tingkat kerentanan daerahnya sedang dan dilihat dari segi sosial, ekonomi dan perkebunan begitu juga dengan kategori tidak rentan yaitu daerah yang memiliki tingkat kerentanannya rendah dilihat dari segi ekonomi, sosial dan perkebunan juga.

\section{HASIL DAN PEMBAHASAN}

\section{Tingkat Kerentanan Sosial.}

Klasifikasi untuk kerentanan sosial yang pertama yaitu status penduduk, yang dilihat yakni dari penduduk asli dan penduduk pendatang.Dari hasil penelitian penduduk asli pada suatu daerah sebelum adanya perkebunan kelapa sawit kondisi sosial nya tinggi dan setelah adanya perkebunan kelapa sawit kondisi sosialnya rendah.pada daerah yang penduduknya berstatus sebagai penduduk pendatang sebelum adanya perkebunan kelapa sawit keadaaan sosialnya kategori sedang dan setelah adanya perkebunan kelapa sawit keadaan sosialnya terlihat lebih rentan.
Pada klasifikasi kedua yaitu pendidikan dimanadaerah dengan pendidikan penduduk tinggi (D3/S1) di kategorikan dengan tidak rentan, secara sosial dibandingkan dengan daerah dengan pendidikan penduduk sedang (SMA/ Sederajat) di kategorikan dengan agak rentan secara sosial, sedangkan penduduk dengan tingkat pendidikan rendah (SD-SMP) dikategorikan sangat rentan secara sosial. Hal ini dikarenakan kualitas pendudukan sangat dipengaruhi oleh tingkat pendidikan.

Pada klasifikasi ketiga untuk kerentanan sosial yaitu kesehatan dimana keterangan petani sawit yang mengindap penyakit dari keseluruhan desa memiliki jawaban yang berbeda. Dimana dapat dijelaskan bahwadari 22 jorong yang ada di kecamatan Sungai Aur yang telah diwawancarai peneliti dilapangan terdapat 8 jorong yang rata-rata penduduknya mengatakan masyarakatnya mengidap penyakit serius yang perlu ditangani dengan pengobatan serius dan penyakit sedang yang tidak perlu di tindak lanjuti, sedangkan 7 jorong lainnya rata-rata masyarakatnya mengatakan penduduknya tidak mengidap penyakit apa-apa.

\section{Hasil Kerentanan Sosial.}

Kerentanan sosial pada Kecamatan Sungai Aur dari hasil penelitian dan pengolahan data untuk setiap parameter kerentanan sosial, diketahuiKecamatan Sungai Aur kategori tingkat kerentanan sosialnya dengan kategori tidak rentan terdapat pada 9 Jorong Yaitu Di Jorong Air Haji, Jorong BPP, Jorong Koto Dalam, Jorong Muara Tapus, Jorong Sikilang, Jorong Sungai Tanang, Jorong Sungai Aurdan untuk kategori agak rentan terdapat 6 jorong yaitu pada Jorong Bayang Tengah, 
Jorong Kumpulan, Jorong Padang Timbalun, Jorong Pematang Sontang, Jorong Simpang Gadang, Jorong Situmang, Jorong Tombang Padang Hilir sedangkan untuk kategori sangat rentan terdapat pada 7 Jorong Yaitu Jorong Bukit Harapan, Jorong Kasik Putih, Jorong Lubuk Juangan, Jorong Sakato Jaya, Jorong Sarasah Betung, Jorong Sarasah Talang, Jorong Sopo Bawak, Jorong UPT
Bukit Melintang.Untuk lebih jelasnya dapat dilihat pada tabel 2 dan gambar 2 .

Tabel 2

Klasifikasi Tingkat Kerentanan Sosial

\begin{tabular}{|l|c|c|c|}
\hline No. & $\begin{array}{c}\text { Tingkat } \\
\text { Kerentanan } \\
\text { Sosial }\end{array}$ & $\begin{array}{c}\text { Jumlah } \\
\text { Jorong }\end{array}$ & Skor \\
\hline 1. & Tidak rentan & 9 & $<7$ \\
\hline 2. & Sedang rentan & 6 & $7-11$ \\
\hline 3. & Sangat rentan & 7 & $>11$ \\
\hline
\end{tabular}

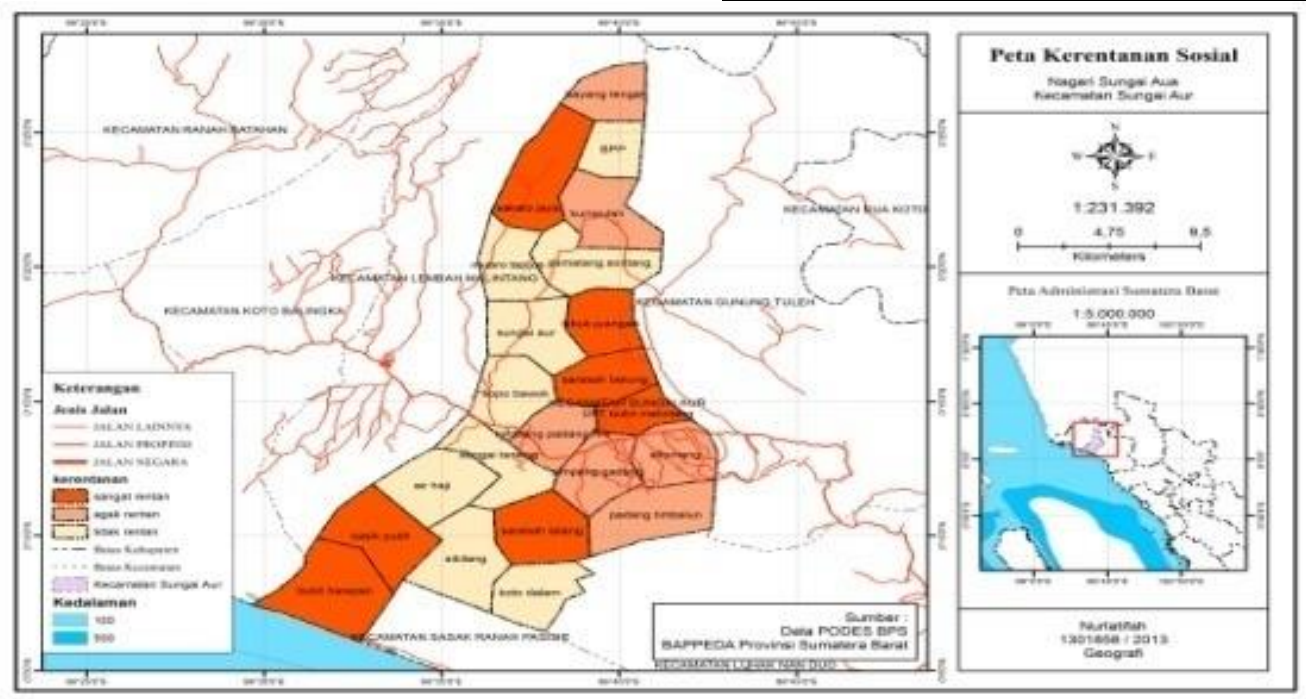

Gambar 2: Peta Kerentanan Sosial Petani Sawit Di Kecamatan Sungai Aur

\section{Kerentanan Ekonomi Masyarakat Petani Sawit Di Kecamatan Sungai Aur}

Pada klasifikasi kerentanan ekonomi yang pertama yaitu status perkebunan kelapa sawit dimanadisini masyarakat yang tergolong rendah (tidak rentan) berdasarkan status perkebunan kelapa sawit yang memiliki perkebunan plasma dan non plasma terdapat pada 9 jorong dan jorong yang tergolong sedang (agak rentan) dengan status perkebunannya rata-rata plasma terdapatpada 5 jorong sedangkan jorong yang tergolong tinggi (sangat rentan) dengan rata-rata status perkebunannya non plasma terdapat pada 8 jorong
Pada klasifikasi kedua yaitu luas perkebunan kelapa sawit dimanaluas kepemilikan lahan yang dimiliki oleh setiap petani sawit berbeda di setiap jorongnya. Dimana dapat dijelaskan bahwa luas kepemilikan lahan yang dimiliki petani sawit pada 22 jorong yang ada di kecamatan Sungai Aur sebanyak 98 orang responden yang telah diwawancarai peneliti dilapangan terdapat jorong yang tergolong rentan, sangat rentan dan tidak rentan, dimana jorong yang tergolong rentan rata-rata pada jorong tersebut mereka hanya memiliki luas lahan kurang dari $2 \mathrm{ha}$ dan jorong yang tergolong agak rentan rata-rata masyarakatnya memiliki luas lahan 1-2 Ha dan jorong yang tergolong tidak rentan 
petaninya rata-rata memiliki luas lahan lebih dari $2 \mathrm{Ha}$.

Jorong yang tergolong rentan dalan klasifikasi luas lahan terdapat 9 jorong yaitu terdiri dari Jorong Bayang Tengah, Jorong BPP, Jorong Kasik Putih, Jorong Lubuk Juangan, Jorong Sarasah Betung, Jorong Sarasah Talang, Jorong Simpang Gadang, Jorong Sopo Bawak, Jorong UPT Bukit Melintang dan jorong yang tergolong agak rentan terdapat 5 jorong yaitu terdiri dari Jorong Bukit Harapan, Jorong Pematang Sontang, Jorong Sakato Jaya, Jorong Situmang, Jorong Tombang Padang Hilir sedangkan jorong yang tergolong tidak rentan terdiri dari 8 jorong yaitu terdiri dari Jorong Air Haji, Jorong Koto Dalam, Jorong Kumpulan, Jorong Muara Tapus, Jorong Padang Timbalun, Jorong Sikilang, Jorong Sungai Aur Dan Jorong Sungai Tanang.

Pada klasifikasi ketiga yaitu pendapatan petani dari perkebunan kelapa sawitdimanarata-rata penghasilan dari hasil panen yang di dapat oleh para petani sawit per bulannya pada setiap jorong responden menjawab. Dimana dapat dijelaskan bahwasannya rata-rata penghasilan yang didapat oleh setiap responden yaitu dari 22 jorong yang ada di kecamatan Sungai Aur dan sebanyak 98 orang responden yang telah diwawancarai peneliti dilapangan mendapatkan jorong yang pendapatan ekonomi petani sawitnya yang rendah (tidak rentan) sebanyak 5 jorong denga rata-rata penghasilan yang mereka terima dari perkebunan kelapa sawit yaitu lebih dari Rp 5.000.000 dan untuk kategori sedang (agak rentan) terdapat 6 jorong denga rata-rata penghasilan yang mereka terima yaitu Rp2.000.000-3.000.000 sedangkan untuk daerah yang tinggi (sangat rentan) terdapat 11 jorong dengan rata-rata penghasilan yang mereka terima yaitu kurang dari $\mathrm{Rp}$ 3.000.000.

Pada kalsifikasi keempat yaitu Pendapatan dari usaha sampingan petani sawit dimanapekerjaan sampingan yang dimiliki oleh petani sawit setiap responden dari semua desa memiliki jawaban yang berbeda. Dimana dapat dijelaskan bahwapekerjaan sampingan yang dimiliki oleh setiap responden yaitu dari 22 jorong yang ada di kecamatan Sungai Aur yang telah diwawancarai peneliti dilapangan terdapat 4 jorong mengatakan bahwa penghasilan yang diterima dari pekerjaan sampingan rata-rata yaitu lebih dari $\mathrm{Rp}$. 3.000.000 dan 12 jorong dalam kategori sedang menjawab penghasilan yang mereka terima dari pekerjaan sampingan rata-rata yaitu Rp1.000.000-2.000.000 dan 6 jorong lainnya termasuk dalam kategori sangat rentan menjawab bahwa penghasilan yang mereka terima dari pekerjaan sampingan yaitu kurang dari Rp 2.000.000. Jadi dari pernyataan diatas dapat disimpulkan bahwasannya lebih banyak responden yang memiliki penghasilan rata-rata Rp1.000.0002.000.000.

Pada klasifikasi ke lima yaitu Tingkat pendapatan masyarakat dari dari seluruh kegiatan usaha yang dimiliki dimanaPenghasilan petani sawit dari seluruh kegiatan usaha yang dimiliki responden dari semua desa memiliki jawaban yang berbeda. Dimana dapat dijelaskan bahwa rata-rata penghasilan dari keseluruhan usaha yang dimiliki responden yaitu dari 22 jorong yang ada di kecamatan Sungai Aur yang telah diwawancarai peneliti dilapangan terdapat 4 
jorong rata-rata menjawab bahwa penghasilan mereka rata-rata di atas $\mathrm{Rp}$. 7.000.000 karena mereka kebanyakan memiliki pekerjaan sampingan juga sebagai petani kelapa sawit, dan 12 jorong lainnya mengatakan rata-rata penghasilan yang didapat dari keseluruhan usaha yang dimiliki sedang antara Rp 3.000.000-Rp 5.000.000 , dan 6 jorong lainnya termasuk rentan dengan rata-rata penghasilan yang mereka miliki setiap bulannya dari keseluruhan usaha yaitu kurang dari Rp 5.000.000.

\section{Hasil Kerentanan Ekonomi}

Kerentanan ekonomi pada Kecamatan Sungai Aur dari hasil penelitian dan pengolahan data untuk setiap parameter kerentanan ekonomi, diketahui Kecamatan sungai aur kategori tingkat kerentanan ekonomi dengan kategori tidak rentan (skor $<11,67)$ terdapat pada 8 jorong yaitu di Jorong Air haji, jorong Koto Dalam, Jorong Muara Tapus, jorong Sikilang, Jorong Sungai Aur, Jorong Sungai Tanang, Jorong
Kumpulan dan untuk kategori Sedang Rentan (skor 11,67-18,33) terdapat 7 jorong yaitu pada Jorong BPP, JorongPadang Timbalun, Jorong Situmang, Jorong Lubuk Juangan, Jorong Pematang Sontang Sedangkan Untuk kategori Sangat Rentan $(>18,33)$ terdapat pada 7 Jorong yaitu Jorong Bayang Tengah, Jorong Bukit Harapan,Jorong Kasik Putih, Jorong Sakato Jaya, jorong SarasahBetung, jorong Sarasah Talang, Jorong Simpang Gadang, Jorong Sopo Bawak, Jorong UPT Jorong Tombang Padang Hilir.Untuk lebih jelasnya dapat dijelaskan pada tabel 3 dan gambar 3.

Tabel 3

Klasifikasi Kerentanan Ekonomi

\begin{tabular}{|l|l|c|c|}
\hline No. & $\begin{array}{c}\text { Tingkat } \\
\text { Kerentanan } \\
\text { Ekonomi }\end{array}$ & $\begin{array}{c}\text { Jumlah } \\
\text { Jorong }\end{array}$ & Skor \\
\hline 1. & Tidak Rentan & 8 & $<12$ \\
\hline 2. & Sedang Rentan & 7 & $12-18$ \\
\hline 3. & Sangat Rentan & 7 & $>18$ \\
\hline
\end{tabular}

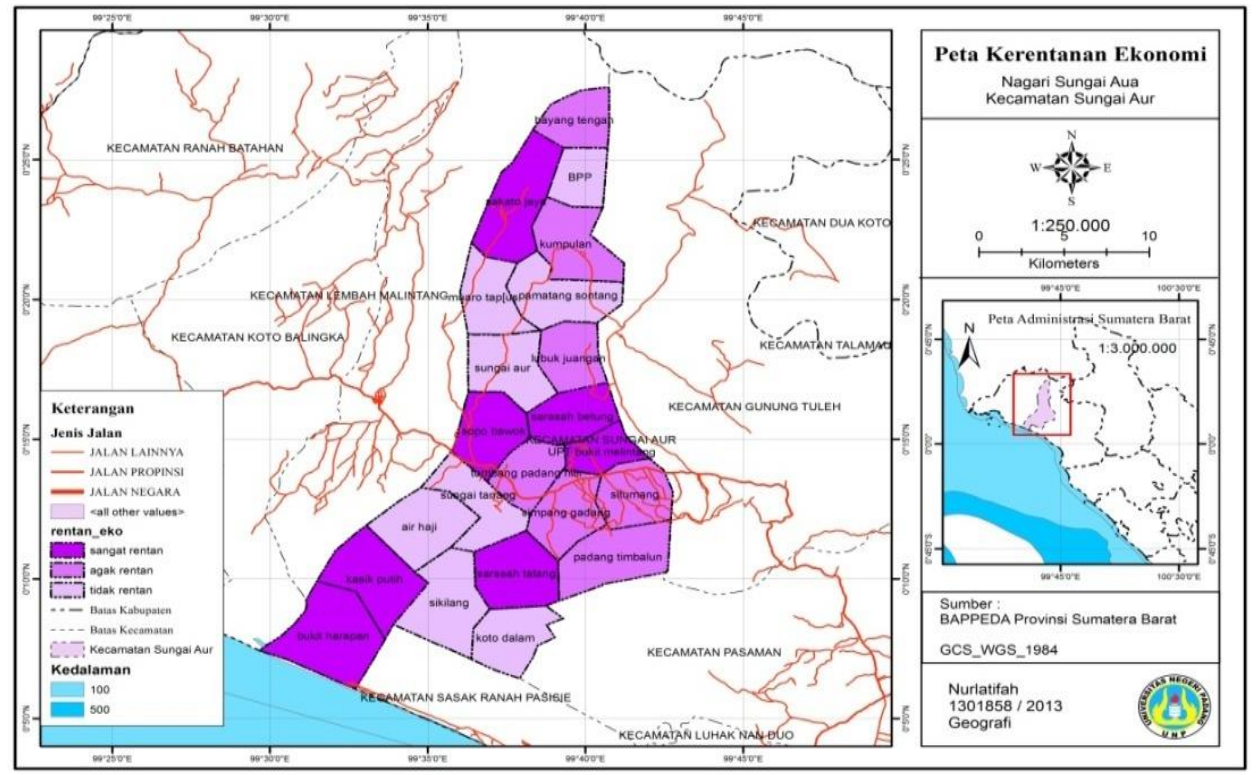

Gambar 3: Peta Kerentanan Ekonomi Petani Sawit Di Kecamatan Sungai Aur.

3. Kerentanan Sosi,al Ekonomi Perkebunan Kelapa Sawit.
Hasil analisis kere,ntanan sosial ekonomi masyarakat di Kecamatan sungai 
aur yang secara langsung ma,upun tidak langsung kehidupannya m,empengaruhi dan dipengaruhi oleh pe,rkebunan kelapa sawit menunjukkan bahw,a tingkat kerentanan sosial ekonomi kela,s kategori tidak rentan (skor kerentanan <,18,67) terdapat pada 4 jorong yaitu joron,g Air haji, jorong Koto Dalam, jorong sungai aur, jorong Sungai Tanang, dan pada, kategori sedang rentan (skor kerentanan 1,8,67-29,34) terdapat pada 9 jorong yaitu, jorong BPP, jorong kumpulan, joron,g Muara Tapus, jorong Padang Timba,lun, jorong Pematang Sontang, joro,ng Situmang, Jorong Tombang Padang Hili,r sedangkan kategori sangat rentan (skor, kerentanan >29,34) terdapat pada 9 jorong yaitu Jorong Bayang Tengah, jorong Bukit Harapan, Jorong Kasik Putih, jorong Lubuk Juangan, jorong
Sakato Jaya, jorong Sarasah Betung, jorong Sarasah Talang,Jorong Sikilang, Jorong Simpang Gadang, jorong Sopo Bawak, Jorong UPT Bukit Melintang. yang terdapat di 22 jorong yang ada di kecamatan Sungai Aur. Untuk lebih jelasnya dapat dijelaskan pada tabel 4 dan gambar 4.

\section{Tabel 4}

Klasifikasi Tingkat Kerentanan Sosial Ekonomi Petani Sawit.

\begin{tabular}{|l|l|c|c|}
\hline No. & $\begin{array}{c}\text { Tingkat } \\
\text { Kerentanan } \\
\text { sosial } \\
\text { Ekonomi }\end{array}$ & $\begin{array}{c}\text { Jumlah } \\
\text { Jorong }\end{array}$ & Skor \\
\hline 1. & Tidak Rentan & 4 & $<19$ \\
\hline 2. & Sedang Rentan & 9 & $\begin{array}{c}19- \\
29\end{array}$ \\
\hline 3. & Sangat Rentan & 9 & $>29$ \\
\hline
\end{tabular}

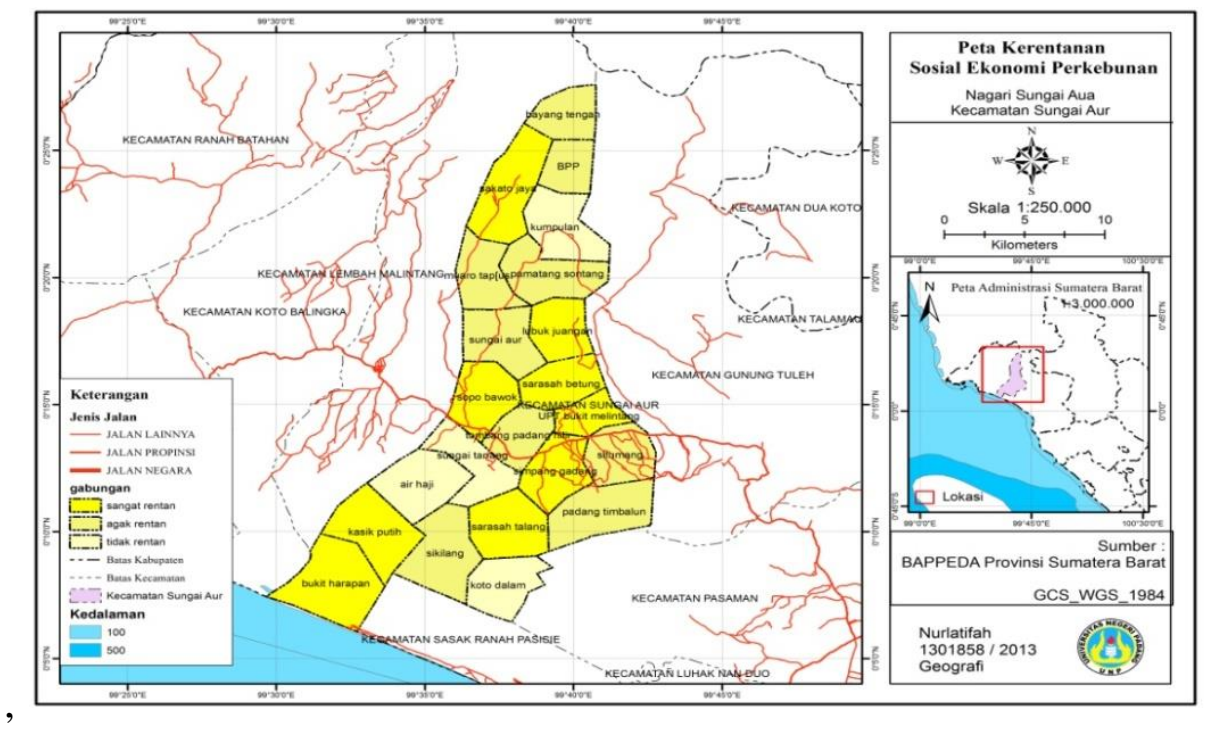

,Gambar 4: Peta Kerentanan Sosial Ekonomi Petani Sawit Di Kecamatan Sungai Aur

\section{Kesimpulan,}

Dari ha,sil penelitian dan pembahasan yang telah, dilakukan pada bab sebelumnya, maka dap,at disimpulkan bahwa:

1. K,erentanan sosial yang ada di Kecamatan Sungai Aur jorong yang di dikategori sangat rentan (nilai >11) yaitu terdapat pada 8 jorong yang terdiri dari Jorong Bukit Harapan, Jorong Kasik Putih, Jorong Sarasah Talang, Jorong Sarasah Betung,, Jorong Sakato Jaya, Jorong Lubuk Juanga,n, Jorong UPT Bukit Melintang, 
Jorong,Sopo Bawak, dan jorong yang dikatego,rikanagak rentan (nilai 4-11) terdap,at 7 jorong yaitu terdapat pada Joro,ng Bayang Tengah, Jorong Kumpulan, Jorong Padang Timbalun, Jorong Simpang Gad,ang, Jorong Situmang, Jorong Tombang P,adang Hilirdan jorong yang di kategorikan, tidak rentan (Nilai <4) terdapat 7 Jorong, Yaitu Pada Jorong Sungai Tanang, Joron,g Sikilang, Jorong Muara Tapus, Joron,g Air Haji,Jorong BPP, Jorong Koto Dala,m.

2. Kerentanan Ekonomi yang ada di Kecamatan Sungai Aur,jorong yang di dikategori sangat (n,ilai >11) yaitu terdapat pada 8 jor,ong yang terdiri dari Jorong Bukit ,Harapan, Jorong Kasik Putih, Jorong,Sarasah Talang, Jorong Sarasah ,Betung, Jorong Sakato Jaya, Jorong L,ubuk Juangan, Jorong UPT Bukit Melintang, Jorong Sopo Bawak, da,n jorong yang dikategorikan agak rent,an (nilai 4-11) terdapat 7 jorong ,yaitu terdapat pada jorong Bayang ,Tengah, jorong Kumpulan, jorong ,Padang Timbalun, jorong Simpan,g Gadang, jorong Situmang, jorong,Tombang Padang Hilirdan joron,g yang di kategorikan tidak rentan (Nilai <4) terdapat 7 jorong yaitu, pada jorong Sungai Tanang, joron,g Sikilang, jorong Muara Tapus, joro,ng Air haji, jorong BPP, jorong Kot,o Dalam.

3. Ke,rentanan perkebunan yang ada di $\mathrm{K}$,ecamatan sungai aur jorong yang di d,ikategori sangat rentan (nilai >6) yaitu terdapat pada 9 jorong yang t,erdiri dari Jorong Bayang Tengah, jorong BPP, Jorong Kasik Putih, Jorong Lubuk Juangan, Jorong
Sarasah Talang, Jorong Sarasah Betung, Jorong UPT Bukit Melintang, Jorong Sopo Bawak, Jorong Simpang GadangDan jorong yang dikategorikan agak rentan (nilai 3-6) terdapat 5 jorong yaitu terdapat pada Jorong Bukit Harapan, Jorong Pematang Sontang, Jorong Sakato Jaya, Jorong Situmang, Jorong Tombang Padang Hilirdan jorong yang di kategorikan tidak rentan (Nilai <3) terdapat 8 jorong yaitu pada Jorong Sungai Tanang, Jorong Sikilang, Jorong Muara Tapus, Jorong Air Haji, Jorong Koto Dalam, Jorong Sungai Aur,Jorong Padang Timbalun, dan Jorong Kumpulan.

Berdasarkan hasil analisis kerentanan sosial ekonomi rumah tangga petani kelapa sawit terhadap perkebunan kelapa sawit di Kecamatan Sungai Uar secara langsung maupun tidak langsung mempengaruhi dan dipengaruhi oleh perkebunan kelapa sawit, dengan menggabungkan seluruh parameter yang ada maka seluruh jorong yang berada di Kecamatan Sungai Aur ini berada pada kerentanan "sangat rentan" dengan skor kerentanan (>28) yang terdapat di 22 jorong yang ada di kecamatan sungai aur. Untuk memperoleh sumber penyebab kerentanan dilakukan penelusuran terhadap parameterparameter yang memiliki nilai tinggi sehingga rekomendasi penanganannya disesuaikan dengan tingkat masalah yang dihadapi. 
Saran,

Adapun saran yang, diberikan dalam penelitian ini yaitu, sebagai berikut:

1. Diharapkan pe,tani kelapa sawit di Kecamatan ,Sungai Aur tidak hanya berg,antung pada hasil kelapa saw,it, tetapi diharapkan petani sawit di Kecamatan Sungai Aur juga, memiliki pekerjaan sampingan, selainmenjadi petani kelapa saw,it.

2. Sebaiknya, petani sawit lebih memperha,tikan pemeliharaan sawit yan,g baik agar hasil yang dipanen, lebih banyak dan bisa mencukupi kebutuhan keluarga mereka.,

3. Peran ,pemerintah sangat diperluk,an untuk memantau, member,ikan penyuluhan untuk kemaju,an perkebunan kelapa sawit.

\section{Daftar Pustaka,}

Lubis, A.U. 2,008. Kelapa Sawit (Elaeis guineens,is Jacq)di Indonesia Edisi ke2 Pusa,t Penelitian Kelapa Sawit. Medan.,

Mardikanto, ,Totok. 2007. Penyuluhan Pemban,gunan Kehutanan. Pusat Penyulu,han Kehutunan Republik Indonesia. Jakarta. 352 Hal.

Tika, H. Mo,h. Panbudu. (2005). Metode Peneliti,an Geografi. Jakarta: Bumi Aksara,

Bambang P,rasetyo. 2006. Metode Penelitia,n Kuantitatif : Teori dan Aplikasi. Raj,a Grafindo Persada : Jakarta.

Antomi, Yudi. 2016. Analisis Perubahan Penggunaan Lahan dan Tingka,t
Kerentanan Sosial Ekonomi untuk

Ekosistem Danau Berkelanjutan

(Studi Kasus Di Kawasan Danau

Maninjau). Disertasi.Pascasarjana

Universitas Indonesia Jakarta. 